\title{
Designing a Turbine Blade Cooling System Using a Generalised Regression Genetic Algorithm
}

\author{
R. Roy ${ }^{1}$, A. Tiwari $^{1}$, J. Corbett $^{1}(1)$ \\ ${ }^{1}$ School of Industrial and Manufacturing Science, Cranfield University, \\ Cranfield, Bedford, MK43 OAL, United Kingdom (UK)
}

\begin{abstract}
The design of a turbine blade cooling system is a multi-objective optimisation problem involving constraints and complex interaction among its design variables. The aim of this paper is to develop a methodology to optimise this design using Evolutionary Computing techniques. This paper presents Generalised Regression Genetic Algorithm (GRGA) and the mathematical model of a real-life turbine blade cooling system. Even in the presence of variable interaction, the methodology identifies a number of good feasible designs from which one could be finally chosen based on designer's preferences. The research also demonstrates that GRGA is capable of optimising a real-life design.
\end{abstract}

\section{Keywords:}

Design, Optimisation, Artificial Intelligence

\section{INTRODUCTION}

Real-life engineering design optimisation problems, as opposed to the theoretical problems (test cases), are those that are encountered in industry. Some examples of these problems are the design of aerospace structures for minimum weight and the surface design of automobiles for improved aesthetics. Along with multiple objectives, constraints, qualitative issues and lack of prior knowledge, most real-life design optimisation problems also involve interaction among decision variables. In spite of its immense potential for real-life problems, lack of systematic research has plagued the field of interaction for a long time. However, in the last two decades, some research has been carried out in this area especially in the field of statistical data analysis [1]. This has been further augmented in the recent past with the growth of computational intelligence techniques such as Evolutionary Computing (EC), Neural Networks (NNs) and Fuzzy Logic (FL). This paper focuses on designing a turbine blade cooling system using a state-of-the-art evolutionary-based optimisation algorithm, Generalised Regression Genetic Algorithm (GRGA). This problem involves three main features of real-life engineering design optimisation problems: multiple objectives, variable interaction and constraints.

\section{INSEPARABLE FUNCTION INTERACTION}

In an ideal situation, desired results could be obtained by varying the decision variables of a given problem in a random fashion independent of each other. However, due to interaction this is not possible in a number of cases, implying that if the value of a given variable changes, the values of others should be changed in a unique way to get the required results. The two types of interaction that can exist among decision variables are inseparable function interaction and variable dependence. Inseparable function interaction is the main focus of this paper. This interaction occurs when the effect that a variable has on the objective function(s) depends on the values of other variables in the function [2]. This concept of interaction can be understood from Figure 1.

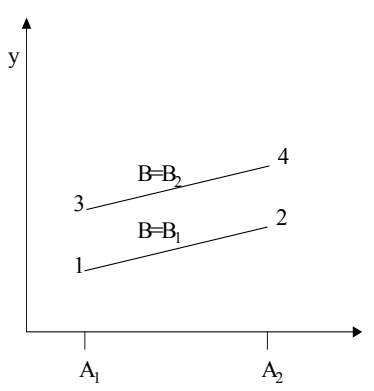

(a)



(b)
Figure 1: An Example of inseparable function interaction (a) No interaction (b) Inseparable function interaction.

\subsection{Challenges posed by inseparable function interaction}

Classical optimisation algorithms, such as Weighted Sum Approach and Goal Programming, suffer from serious limitations in dealing with the complexities introduced by inseparable function interaction in multiobjective optimisation problems. A Genetic Algorithm (GA) operates on the building blocks, growing them and mixing them with each other in an attempt to solve the search problem at hand. The inseparable function interaction also causes problems for a GA by making it more difficult for it to build these building blocks. Furthermore, in its presence, a multi-objective optimisation problem cannot be decomposed into simpler parts. Hence, a GA requires updating all decision variables in a unique way in order to attain the desired results. With a generic search operator, this becomes a difficult task for the GA. Furthermore, even if a set of optimal solutions are obtained, it is difficult to maintain them since any change in one variable must be accompanied by related changes in others [3].

\subsection{Techniques for handling inseparable function interaction}

A number of research questions remain unanswered regarding the theory of inseparable function interaction. 
However, from the practical point of view a number of Evolutionary Computing techniques have been developed. But these techniques can only deal with single-objective optimisation problems, defined in discrete domains. The few techniques that are available for dealing with real search spaces have limited capability in terms of handling any significant inseparable function interaction. Recently the authors addressed the above-identified research gap by presenting a technique called GRGA for dealing with hybrid-valued (with integer and real variables) multi-objective optimisation problems [4]. As shown in the next section, the design of a turbine blade cooling system has high degrees of inseparable function interaction among its decision variables. Therefore, the paper applies GRGA for dealing with this problem.

Film

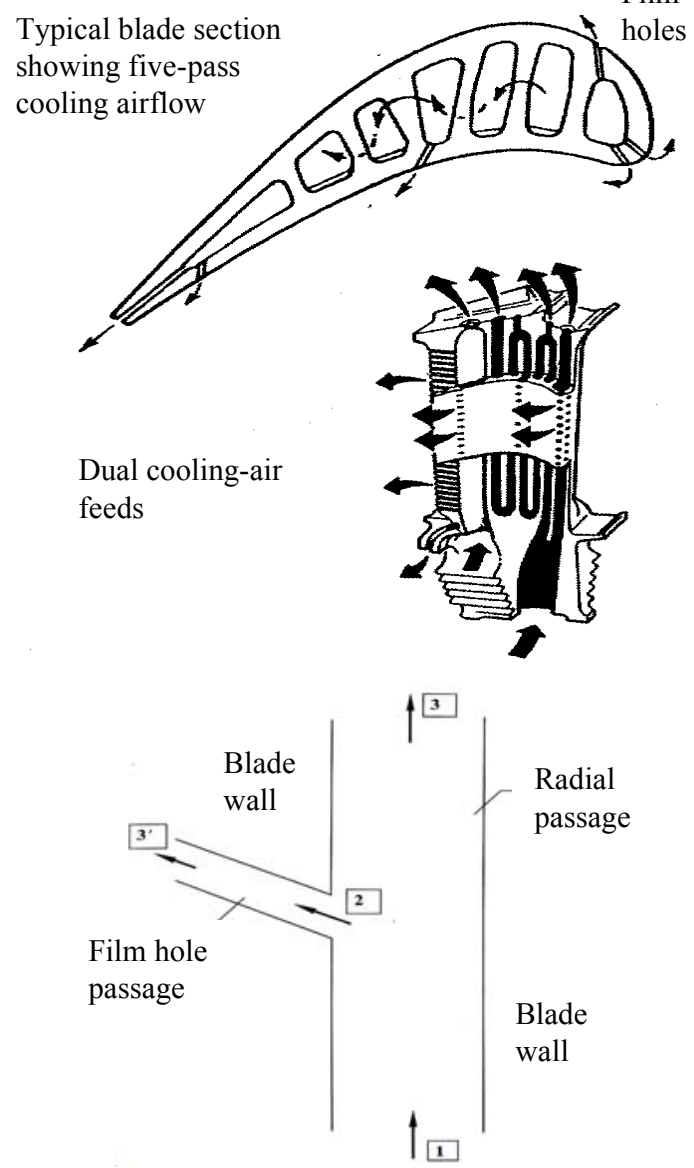

Figure 2: Design of a turbine blade cooling system [5].

\section{DESIGN OF A TURBINE BLADE COOLING SYSTEM}

In order to maximise gas turbine engine performance and efficiency, turbine blades need to operate in an environment where the gas temperature is as high as possible. This temperature often exceeds the operational limits of the turbine blade materials. To ensure component integrity whilst operating at high gas temperatures, blade materials are cooled to safe operating temperature levels by passing relatively cool air through them and in more extreme cases, over them in the form of films. A small portion of the compressor exit airflow is utilised for this purpose (Figure 2). The temperature of this cooling air depends on the compressor pressure ratio and on the flight Mach number and temperature. The sacrifices for the blade cooling include the loss of work (and some loss of efficiency) due to the portion of the air taken from the compressor exit [5].

\begin{tabular}{|c|c|c|}
\hline Step & Task & Comments \\
\hline 1 & Estimate $\mathrm{W}_{\mathrm{cr}}$ & $\begin{array}{l}\text { Based on the limiting value } \\
\text { of flow off-take from the } \\
\text { engine compressor. }\end{array}$ \\
\hline 2 & Estimate $\mathrm{T}_{\mathrm{wg}}$ & $\begin{array}{l}\text { Based on material property } \\
\text { limitation, suggested } \\
1500 \mathrm{~K} \text {. }\end{array}$ \\
\hline 3 & Calculate $\mathrm{h}_{\mathrm{cr}}$ & - \\
\hline 4 & Calculate $\mathrm{A}_{\mathrm{cr}}$ & $\begin{array}{l}\text { If within the limiting value of } \\
A_{c r} \text { go to Step } 5 \text {. If not, } \\
W_{c r}=W_{c r}{ }^{*} 0.99 \text { and go back } \\
\text { to Step } 4 \text {. }\end{array}$ \\
\hline 5 & Calculate $\mathrm{W}_{\mathrm{cr}}$ & - \\
\hline 6 & Calculate $\mathrm{h}_{\mathrm{cr}}$ & $\begin{array}{l}\text { Compare } \mathrm{h}_{\mathrm{cr}} \text { value from } \\
\text { Step } 6 \text { with Step } 3 \text {. If within } \\
\text { tolerance then proceed to } \\
\text { check whether } \mathrm{h}_{\mathrm{cr}} \text { lies } \\
\text { within the acceptable } \\
\text { range. If yes, go to Step } 7 \\
\text { otherwise reset the } \mathrm{T}_{\mathrm{wg}} \text { and } \\
\mathrm{h}_{\mathrm{cr}} \text { values and go to Step } 4 \text {. } \\
\text { If the wall temperature } \\
\text { calculation reaches a } \\
\text { steady state then only } \\
\text { accept, if not go back to } \\
\text { Step } 4 \text {. }\end{array}$ \\
\hline 7 & Calculate $\mathrm{T}_{\mathrm{wg}}$ & $\begin{array}{l}\text { If within the acceptable limit } \\
\text { then accept. If not and if } \\
W_{c r} \text { has not been changed } \\
\text { previously, change } W_{c r} \text { to } \\
W_{c r}=W_{c r}{ }^{*} 1.01 \text {. }\end{array}$ \\
\hline 8 & Calculate $T_{c}$ & - \\
\hline 9 & Recalculate k & - \\
\hline 10 & Recalculate $\mu$ & $\begin{array}{l}\text { Reset } T_{w g} \text { and } h_{c r} \text { values } \\
\text { and go to Step } 4 . \text { If the wall } \\
\text { temperature calculation } \\
\text { reaches a steady state } \\
\text { then only accept. }\end{array}$ \\
\hline
\end{tabular}

Table 1: Cooling system design procedure used in TBCOM [5].

The Turbine Blade COoling system Model (TBCOM) is presented in detail by Roy [5] considering one dimensional, single pass coolant flow. The objectives in this optimisation problem are to minimise:

- coolant mass flow for radial passage $\left(\mathrm{W}_{\mathrm{cr}}\right.$ in $\left.\mathrm{Kg} / \mathrm{s}\right)$;

- metal temperature for gas side ( $T_{\mathrm{wg}}$ in $\left.\mathrm{K}\right)$.

This problem has twelve variables as given below:

- type of geometry (Geom);

- coefficient of discharge (radial passage) $\left(\mathrm{C}_{\mathrm{dr}}\right)$;

- heat transfer coefficient factor (radial passage) $\left(F_{\mathrm{hc}}\right)$;

- inlet temperature $\left(\mathrm{Tc}_{1}\right)$;

- wall thickness (dth);

- thermal conductivity of the blade material $\left(\mathrm{k}_{\mathrm{w}}\right)$;

- pressure ratio $\left(\mathrm{R}_{\mathrm{p}}=\mathrm{Pc}_{1} / \mathrm{Pc}_{3}\right)$;

- perimeter ratio (radial passage) $\left(\mathrm{R}_{\mathrm{s}}=\mathrm{S}_{\mathrm{gr}} / \mathrm{S}_{\mathrm{cr}}\right)$;

- film hole diameter (df);

- coefficient of discharge (film hole) $\left(\mathrm{C}_{\mathrm{df}}\right)$;

- heat transfer coefficient factor (film hole) $\left(F_{f}\right)$;

- pressure ratio (film) $\left(\mathrm{R}_{\mathrm{pf}}=\left(\mathrm{Pc}_{1}-\mathrm{Pc}_{2}\right) /\left(\mathrm{Pc}_{1}-\mathrm{PC}_{3}\right)\right)$. 
In this problem, the first variable is discrete (plane ribbed or pedestal) and the rest are real. Also, the values of $\mathrm{C}_{\mathrm{dr}}$ and $\mathrm{F}_{\mathrm{hc}}$ vary within a range according to the type of geometry. This problem also has 15 constraints that include limits on the above-mentioned variables, blade wall temperature (on the gas and film side) and flow ratio $\left(\mathrm{W}_{\mathrm{cr}} / \mathrm{W}_{\mathrm{cf}}\right)$.

This problem is non-linear and multi-dimensional in nature, and has a biased search space. The objective functions are implicit and multi-layered. Hence, the determination of objective values requires an iterative procedure in which the effect that a variable has on the objective functions depends on the values of other variable in the function. It is evident from this discussion that the design of a turbine blade cooling system is a multi-objective optimisation problem involving high degrees of inseparable function interaction. Since GRGA is capable of successfully handling complex inseparable function interaction [4], it is chosen for application to this problem. The next section briefly describes GRGA.

The cooling system design procedure and the equations involved are detailed in Roy [5]. Here, the iterative design procedure used for the calculation of the values of $W_{c r}$ and $T_{w g}$ is shown in Table 1 to give an illustration of the model complexity and its equations. Literature does not report the application of any multi-objective optimisation algorithm on this problem.

\section{GENERALISED REGRESSION GA (GRGA)}

The optimal solutions of a multi-objective optimisation problem lie on a front called the Pareto front. For any continuous portion of the Pareto front, there is a unique relationship involving objective functions. This relationship is difficult to obtain analytically, and even if it is found, it has limited usefulness since mapping from function space to variable space is very complex. However, the existence of a relationship among objective functions of Pareto solutions necessarily implies that corresponding relationship(s) exist among the decision variables of these solutions [6].

A simple multi-objective optimisation problem is used below for explaining the above concept. Consider a twoobjective optimisation problem having $f_{1}$ and $f_{2}$ as the two objective functions. For any continuous portion of the Pareto front, there exists a Function $F$ involving $f_{1}$ and $f_{2}$ Suppose the problem has two decision variables $x_{1}$ and $x_{2}$ that define the functions $f_{1}$ and $f_{2}$ i.e. $f_{1}$ and $f_{2}$ can be expressed as $f_{1}\left(x_{1}, x_{2}\right)$ and $f_{2}\left(x_{1}, x_{2}\right)$, leading to $F_{1}$.

$$
\begin{aligned}
& F\left(f_{1}, f_{2}\right)=0, \\
& F\left(f_{1}\left(x_{1}, x_{2}\right), f_{2}\left(x_{1}, x_{2}\right)\right)=0, \\
& \Rightarrow F_{1}\left(x_{1}, x_{2}\right)=0 .
\end{aligned}
$$

This proves the statement made earlier that there is existence of relationship(s) among the variables of the solutions belonging to any continuous portion of the Pareto front. GRGA aims to explore this relationship using non-linear multi-variable regression analysis [1]. It uses the relationship thus obtained to (Figure 3):

- perform periodic and final re-distribution of solutions for aiding their spread;

- use history of change of regression coefficients for guiding the search towards the Pareto front;

- use rate of change of regression coefficients as the termination condition of the algorithm.

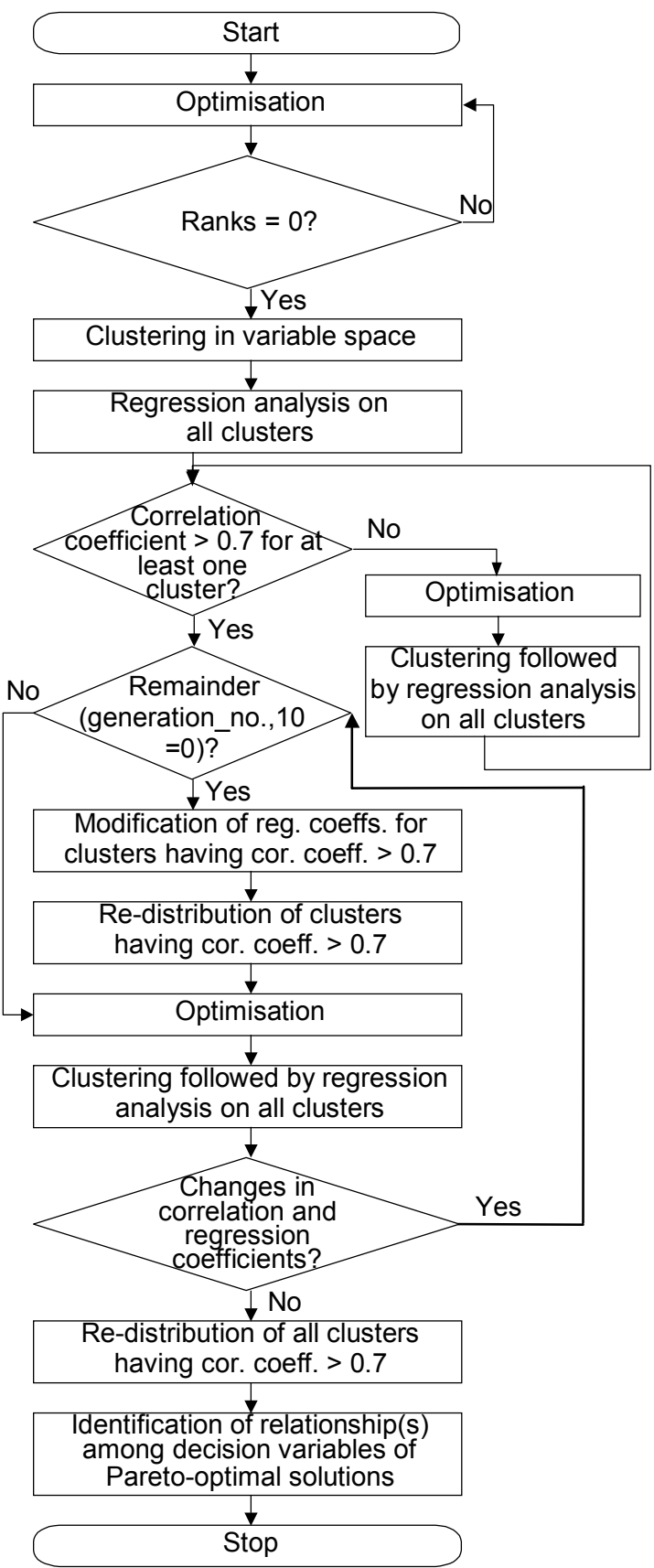

Figure 3: Generalised Regression GA (GRGA) [6].

\section{EXPERIMENTAL RESULTS}

In the experimental results reported in this section, two objectives are considered for optimisation $\left(\mathrm{W}_{\mathrm{cr}}\right.$ and $\left.\mathrm{T}_{\mathrm{wg}}\right)$, and all the constraints in the problem are incorporated. Figure 4 compares the results from GRGA with those from NSGA-II, a high performing evolutionary-based multi-objective optimisation algorithm [3]. All the tests reported here are carried out using 100 population size, 500 generations, 0.8 crossover probability, 0.05 mutation probability, and simulated binary crossover with 10 crossover distribution index and 50 mutation distribution index. These results form the typical set obtained from 10 runs with different seed values for the random number generator. No major variation was observed in the results with the change in seed values. 

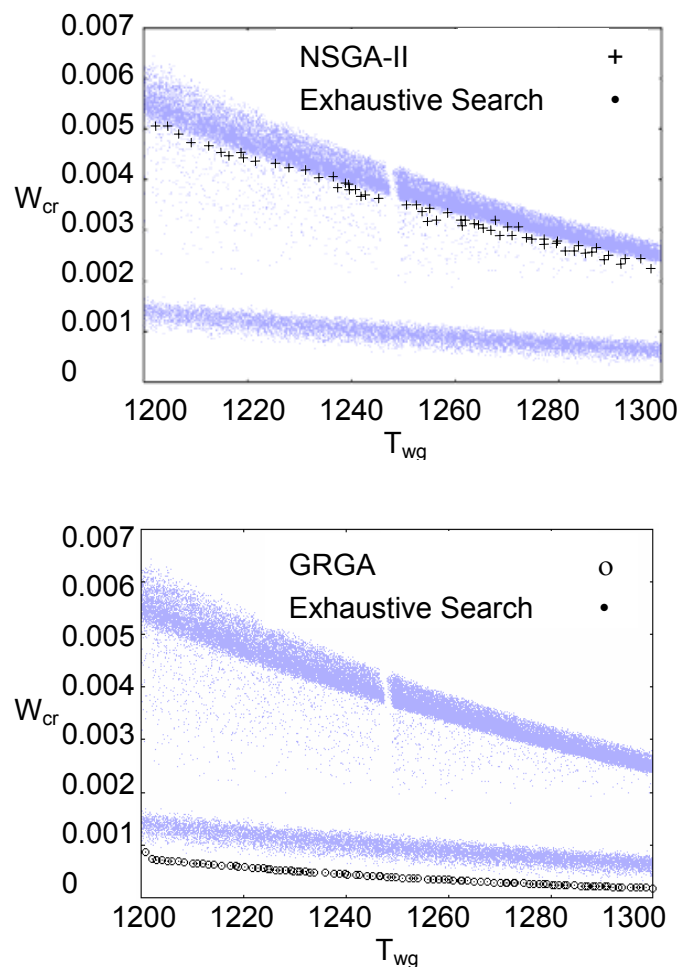

Figure 4: Experimental results (assuming two objectives) (units: $\mathrm{W}_{\mathrm{cr}}$ in $\mathrm{Kg} / \mathrm{s}, \mathrm{T}_{\mathrm{wg}}$ in $\mathrm{K}$ ).

\section{DISCUSSION OF RESULTS}

The following observations can be made regarding the search space of this problem (Figure 4):

- A Pareto front appears in the plot, implying conflict between $W_{c r}$ and $T_{w g}$. This is intuitive since any increase in coolant mass flow is expected to decrease the metal temperature and vice versa. The search space also has bias towards high $\mathrm{T}_{\mathrm{wg}}$ values.

- The $\mathrm{W}_{\mathrm{cr}}-\mathrm{T}_{\mathrm{wg}}$ plot also depicts that the given model has a local and a global Pareto front with respect to $\mathrm{W}_{\mathrm{cr}}$ and $\mathrm{T}_{\mathrm{wg}}$. This multi-modality arises due to the presence of a discrete variable in the problem. This also causes very low density of population in the region between the two fronts, leading to deception in the search space.

- This model has 12 variable bounds and 3 constraints. These 3 constraints focus the plot in the given range of $\mathrm{W}_{\mathrm{cr}}$ and $\mathrm{T}_{\mathrm{wg}}$, introduce an infeasible region in the $W_{c r}-W_{c f}$ space and create sparsely populated regions that correspond to the values of $\mathrm{W}_{\mathrm{cr}}$ close to 0.002 .

The experimental results depicted in Figure 4 are analysed here to make the following observations:

- NSGA-II gets trapped in the local front but GRGA is able to successfully converge to the global Pareto front. Due to this convergence, GRGA is able to determine the relationships involving those decision variables that define the Pareto front. Therefore, when it uses these values to redistribute the final solutions, the results that are attained lie on the Pareto front and are well distributed across it.

- The Pareto front of this problem has fixed values for 11 variables. Here, GRGA reveals that the Pareto front corresponds to Geom $=$ pedestal, $\mathrm{C}_{\mathrm{dr}}=0.3995$, $\mathrm{F}_{\mathrm{hc}}=3.199, \mathrm{Tc}_{1}=799.05, \mathrm{dth}=0.0024381, \mathrm{k}_{\mathrm{w}}=$
19.19, $R_{p}=1.5933, d f=0.0001041, C_{d f}=0.7491, F_{f}$ $=1.497$ and $R_{\mathrm{pf}}=0.397$. Therefore, to attain any solution on the Pareto front, the designer needs to fix the above-mentioned variables to these values, and choose a suitable value for the variable $R_{s}$ based on his/her preferences.

Roy [5] applied Adaptive Restricted Tournament Selection (ARTS) to this problem, but considering only one objective, $W_{c r}$. The results obtained from ARTS lie on the global Pareto front, but as expected, are concentrated at its extreme end that corresponds to low values of $\mathrm{W}_{\mathrm{cr}}$ and high values of $\mathrm{T}_{\mathrm{wg}}$.

\section{FUTURE RESEARCH ACTIVITIES AND CONCLUSIONS}

The limitations of the current methodology and the corresponding future research activities are as follows:

- The performance of GRGA is dependent on how accurately the relationship among decision variables can be represented by RA. Hence, use of more sophisticated non-linear modelling tools have the potential of improving its performance.

- GRGA needs to be further improved to make it more scalable with respect to the number of objectives and dimensions.

- Both the TBCOM and GRGA need to be enhanced to incorporate qualitative issues such as manufacturability and designers' preferences.

This paper has demonstrated that the optimisation of a turbine blade cooling system design is a challenging problem due to the presence of complex inseparable function interaction among its decision variables. An evolutionary-based multi-objective optimisation algorithm, GRGA, has been applied to this problem. The paper has established that GRGA successfully handles complex inseparable function interaction to identify a range of optimum feasible designs from which one could be finally chosen based on designer's preferences.

\section{ACKNOWLEDGEMENTS}

The authors wish to acknowledge the support of the Engineering and Physical Sciences Research Council (EPSRC) - Grant No. GR/M 71473, Nissan Technical Centre - Europe (NTC-E) and Structural Dynamics Research Corporation (SDRC) UK.

\section{REFERENCES}

[1] Draper, N.R., Smith, H., 1998, Applied Regression Analysis, John Wiley \& Sons, Inc., New York, USA.

[2] Taguchi, G., 1987, System of Experimental Design - Vol. 1, UNIPUB/Kraus International Publications, New York, USA.

[3] Deb, K., 2001, Multi-objective Optimization Using Evolutionary Algorithms, John Wiley \& Sons, Inc., New York, USA.

[4] Tiwari, A., Roy, R., Jared, G. and Munaux, O., 2002, Evolutionary-based Techniques for Real-life Optimisation: Development and Testing, Applied Soft Computing Journal, 1/4F:301-329.

[5] Roy, R., 1997, Adaptive Search and the Preliminary Design of Gas Turbine Blade Cooling System, PhD. Thesis, EDC, University of Plymouth, UK.

[6] Tiwari, A., 2001, Evolutionary Computing Techniques for Handling Variable Interaction in Engineering Design Optimisation, PhD. Thesis, SIMS, Cranfield University, UK. 